\title{
O SIGNIFICADO DE SER FAMILIAR CUIDADOR DO PORTADOR DE TRANSTORNO MENTAL
}

\author{
Marília Mazzuco Sant'Anaํ, Valdete Preve Pereira², Miriam Süsskind Borenstein ${ }^{3}$, Alcione Leite da Silva ${ }^{4}$
}

\footnotetext{
${ }^{1}$ Enfermeira. Santa Catarina, Brasil. E-mail: ma_mazzuco@yahoo.com.br

${ }^{2}$ Mestre em Enfermagem. Professora do Curso de Enfermagem da Universidade do Vale do Itajaí - Campus Biguaçu. Enfermeira Psiquiátrica do Instituto de Psiquiatria de Santa Catarina. Santa Catarina, Brasil. E-mail: detepreve@yahoo.com.br

${ }^{3}$ Doutora em Filosofia da Enfermagem. Professora do Departamento de Enfermagem e do Programa de Pós-Graduação em Enfermagem da Universidade Federal de Santa Catarina. Santa Catarina, Brasil. E-mail: miriam@nfr.ufsc.br

${ }^{4}$ Doutora em Filosofia da Enfermagem. Professora do Seç̧ão Autónoma de Ciências da Saúde da Universidade de Aveiro, Portugal. E-mail: alsilva@ua.pt
}

RESUMO: Trata-se de um estudo qualitativo, do tipo exploratório, descritivo, cujo objetivo foi compreender os significados de ser familiar cuidador do paciente portador de transtorno mental. O estudo foi desenvolvido com familiares de portadores de transtornos mentais, atendidos na Clínica Integrada de Atenção Básica à Saúde, no município de Biguaçu-SC, vinculada à Universidade do Vale do Itajaí. Dados qualitativos foram obtidos por entrevista dialógica e analisados com base na teoria do Tornar-se Humano. Da análise dos dados emergiram as seguintes categorias: e a experiência do transtorno mental em família; o enfrentamento das dificuldades e limitações; a interrelação em família e com "outros"; a co-criação das possibilidades de transcendência. Concluiu-se que viver a teoria do Tornar-se Humano com o familiar cuidador do portador de transtorno mental, implica na co-participação do(a) enfermeiro(a) na iluminação dos significados das situações vivenciadas, co-transcendendo as suas próprias condições de ser e agir no mundo, na busca de melhor qualidade de vida.

DESCRITORES: Enfermagem. Transtornos mentais. Família.

\section{THE MEANING OF GIVING MENTAL HEALTH CARE TO FAMILY}

\begin{abstract}
The objective of this qualitative, exploratory, and descriptive study was to understand the meanings of being a caregiver to family members with mental disorders. The study was conducted among relatives of patients with mental disorders, attended at the Integrated Clinic of Primary Health Care in the municipality of Biguaçu-SC, Universidade do Vale do Itajaí. Qualitative data was generated through dialogic interviews and analyzed using the theory of Becoming Human. Four categories emerged from analysis: the experience of mental disorder in families; coping with its difficulties and limitations; relationships with family and "others"; co-creation of the possibilities for transcendence. We conclude that living the theory of Becoming Human including a family member mental patient caregiver involves the co-participation of the nurse as a caregiver, in illuminating with meaning the experienced situations, thus co-transcending their own conditions of being and acting in the world in search of a better quality of life.
\end{abstract}

DESCRIPTORS: Nursing. Mental disorders. Family.

\section{EL SIGNIFICADO DE SER EL CUIDADOR FAMILIAR DE PACIENTES MENTALES}

RESUMEN: Este es un estudio cualitativo de enfoque exploratorio, descriptivo, cuyo objetivo fue comprender el significado de ser un cuidador familiar de pacientes con trastornos mentales. El estudio se desarrolló con los familiares de los pacientes con trastornos mentales, seguido en la clinica integrada de Atención Primaria de Salud en el municipio de Biguaçu-SC, vinculada a Universidade do Vale do Itajaí. Los datos cualitativos fueron obtenidos por entrevista dialógica y analizados sobre la base de la teoría del Devenir Humano. Del análisis de los dados surgieron las siguientes categorías: la experiencia de trastorno mental en las familias; hacer frente a las dificultades y limitaciones, la interrelación con la familia y "otros"; y co-creación de las posibilidades de trascendencia. Se concluyó que viver la teoría del Devenir Humano con el familiar cuidador de pacientes con trastorno mental, implica la co-participación del enfermero en la iluminación de los significados de las situaciones vivenciadas, co-trasciendendo sus propias condiciones de ser y actuar en el mundo en busca de una mejor calidad de vida.

DESCRIPTORES: Enfermería. Transtornos mentales. Família. 


\section{INTRODUÇÃO}

As atuais políticas públicas brasileiras de saúde mental priorizam a desospitalização e a desinstitucionalização da assistência, e tornam a família, a principal responsável pelo cuidado do doente. ${ }^{1}$ Nestas modalidades de atendimento, os pacientes recebem o acompanhamento médico que necessitam, em regime ambulatorial, e permanecem com suas famílias. ${ }^{2}$

Com a permanência dos pacientes em casa, passaram a fazer parte da rotina familiar: garantir as suas necessidades básicas; coordenar suas atividades diárias; administrar sua medicação; acompanhá-los aos serviços de saúde; lidar com seus comportamentos problemáticos e episódios de crise, fornecer-lhes suporte social; arcar com seus gastos; e superar as dificuldades dessas tarefas e seu impacto na vida social e profissional do familiar. ${ }^{3}$

Com isso, as transformações, que vem ocorrendo na saúde mental, visam inserir os portadores de transtorno mental e seus familiares como protagonistas de um processo que busca inovar as formas de atenção; também, contam com a parceria dos profissionais desta área, que atuam nos diversos cenários, atendendo a essa população, baseando-se no acolhimento, no estabelecimento de vínculos, na responsabilização e na ética do cuidado. ${ }^{4}$

Porém, a família é, na maioria das vezes, o suporte de acolhimento do doente mental, além dos demais profissionais de saúde que atuam na rede de saúde mental. Os familiares passam, então, a conviver mais de perto com o portador de transtorno mental, situação que tende a gerar mais dificuldades no relacionamento, sofrimentos e, por vezes, reinternações do doente. ${ }^{5}$

Os familiares de portadores de transtornos mentais, a partir do momento que se deparam com esta situação, sofrem uma significativa mudança em suas vidas, tendo que se adaptarem constantemente às novas formas de condução do seu dia-a-dia. Toda esta mudança repercute sobre vários aspectos do estilo de vida de cada família acometida por esse transtorno. Dados os transtornos enfrentados pelas famílias, as equipes de saúde mental devem, para além do doente, incluí-las no processo de cuidado à saúde.

Neste contexto, é indispensável identificar a compreensão que as famílias tem a respeito da doença mental e as possíveis formas de cuidado à saúde, conhecer os significados e experiências destas famílias, e oferecer alternativas de cuidado à saúde e interação para lidar com a doença, com as dificuldades na aceitação e enfrentamento. Oportunizar, também, apoio à adaptação a um novo estilo de vida e à significativa mudança que pode ocorrer em toda a família acometida por algum transtorno mental.

$\mathrm{Na}$ assistência psiquiátrica, é fundamental que "o profissional tenha capacidade empática com o sofrimento do outro, disponibilidade interna para a escuta, flexibilidade para mudar seus pontos de vista" 6:60, proporcionando um elo que liga a família, na busca do processo terapêutico. Por sua vez, a Enfermagem Psiquiátrica pode ser definida como "um processo interpessoal que promove e mantém um comportamento do paciente (indivíduo, família ou comunidade)"7:36, proporcionando integração para o seu funcionamento.

Para atuar junto às famílias de portadores de transtornos mentais, é importante que o enfermeiro conheça e compreenda a estrutura familiar, suas crenças, valores e conhecimento sobre a doença, para que, a partir daí, possa planejar a sua assistência conforme a necessidade desses familiares. "O trabalho do enfermeiro, em Enfermagem em Saúde Mental e Psiquiátrica, envolve parceria com o cliente e a família, para atender as múltiplas facetas do transtorno mental" $8: 35$

Visando preencher as lacunas de conhecimento na área da saúde mental envolvendo o familiar cuidador e a atuação da Enfermagem Psiquiátrica como elo para estabelecer as relações interpessoais terapêuticas, desenvolvemos um estudo, com o objetivo de compreender os significados de ser familiar cuidador do paciente portador de transtorno mental. O referencial teórico adotado foi a teoria do "Tornar-se Humano" ${ }^{\text {, }}$, por ser apropriada ao desenvolvimento deste estudo. Essa teoria, baseada nas ciências humanas, emerge de uma síntese criativa de conceitos e caracteriza a singularidade da enfermagem. Descreve o ser humano unitário, co-criando saúde, a partir de sua dinâmica relação com o meio ambiente. Tem como foco a qualidade de vida, a partir da perspectiva da pessoa. O ser humano, a partir dos significados de suas experiências vividas, é capaz de co-criar novas possibilidades de vida e saúde, co-transcender este significado, buscando "ir além". Cabe à enfermeira apoiar o ser humano na estruturação de significados que emergem das situações cotidianas de suas vidas, co-criando padrões rítmicos de relações e co-transcendendo com as possibilidades de vida e saúde. ${ }^{9}$ 


\section{METODOLOGIA}

Trata-se de um estudo qualitativo, do tipo exploratório-descritivo, no qual foi utilizada a abordagem metodológica da teoria "Tornar-se humano". ${ }^{9}$

Participaram do estudo duas famílias de portadores de transtorno mental, num total de três familiares cuidadores, atendidos na Clínica Integrada de Atenção Básica à Saúde (CIABS), no município de Biguaçu-SC. Os participantes foram indicados pela equipe do Programa de Saúde da Família (PSF), que atua na assistência em saúde mental da CIABS. Os encontros foram agendados no primeiro dia de contato com cada familiar, de acordo com a disponibilidade dos mesmos.

O estudo seguiu as orientações da Resolução $n^{0}$ 196/96, do Conselho Nacional de Saúde (CNS) ${ }^{10}$, que aborda a ética em pesquisa envolvendo seres humanos. Os participantes foram informados sobre os direitos de participar ou não da pesquisa e da possibilidade de desistir em qualquer fase da mesma, e ainda, sobre o Termo de Consentimento Livre e Esclarecido. Somente após a concordância e assinatura do Termo, os dados passaram a serem coletados. A pesquisa foi aprovada pela instituição e pelo CONEP, com Certificado de Apresentação para Apreciação Ética, sob o número 0005.0.223.000-07, de 02/04/2007.

Por motivos éticos, os nomes dos familiares foram substituídos pelos seguintes pseudônimos: Rubi, Diamante e Esmeralda.

Rubi e Diamante são casados há mais de 20 anos e aparentam idade entre 40 e 50 anos. Rubi é mulher e Diamante é homem. São pais de dois filhos, uma menina de nove anos e um rapaz de 25 anos, que tem diagnóstico médico de Transtorno Afetivo Bipolar. Rubi e Diamante são os cuidadores nesta família. Esmeralda é uma mulher que aparenta, aproximadamente, 40 anos, é casada, não tem filhos, cuida de sua mãe de 71 anos e vive com ela e com o marido há cinco anos. A mãe tem diagnóstico médico de depressão. Esmeralda é a quinta filha, pela ordem de idade, e é a cuidadora nesta família.

A coleta dos dados foi realizada no período de julho a agosto de 2007. Desenvolveu-se através de entrevistas dialógicas em seis encontros, numa sala da CIABS, e também, na residência de uma família, pela impossibilidade do participante comparecer à unidade.

A dinâmica das entrevistas dialógicas foi baseada nos três princípios da Teoria do "Tornar- se humano" $\left.{ }^{\prime \prime}: 1\right)$ estruturar significados multidimensionalmente é co-criar a realidade, através da comunicação de valores e imagens; 2) co-criar padrões rítmicos de relações é viver, ao mesmo tempo, as unidades paradoxais de revelar-ocultar e capacitar-limitar enquanto conecta-separa; 3) co-transcender com as possibilidades é reforçar formas singulares de se originar no processo de transformação. Nos encontros dialógicos estimulamos a reflexividade sobre as experiências vividas, focando e iluminando os significados destas experiências, enquanto unidade viva de saúde. Nesta perspectiva, o enfermeiro é o articulador entre as experiências vividas e a construção dos novos conhecimentos, procurando mobilizar a transcendência para ir além do significado do momento, para aquilo que ainda não é. ${ }^{11}$

$\mathrm{O}$ registro dos dados foi realizado por meio de gravação em áudio e diários de campo, contendo notas pessoais acerca dos encontros. Após este processo, os dados foram transcritos, categorizados e analisados no decorrer do estudo. Baseados nos passos metodológicos propostos pela autora da Teoria do "Tornar-se humano", a análise dos dados seguiu a extração de síntese e a interpretação heurística. Na extração de síntese, a essência foi obtida a partir dos diálogos realizados entre a enfermeira e o familiar cuidador do portador de transtorno mental, possibilitando uma estrutura que demonstrasse a reflexão dos significados destas vivências. A interpretação heurística se deu através da interpretação dos significados, tal como descritos na linguagem dos participantes, no decorrer do processo, integrando as estruturas da teoria e suas concepções metodológicas.

\section{APRESENTAÇÃO E DISCUSSÃO DOS RESULTADOS}

Da análise dos dados emergiram quatro categorias temáticas que indicaram os significados de ser familiar cuidador do paciente portador de transtorno mental, as quais foram: a experiência do transtorno mental em família; o enfrentamento de dificuldades e limitações; a interrelação em família e com "outros"; e a co-criação das possibilidades de transcendência.

\section{A experiência do transtorno mental em família}

Cuidar da pessoa portadora de transtorno mental impõe ao familiar situações associadas aos sintomas da doença, com as quais nem sempre está 
preparado para lidar. Estas situações incluem comportamentos de descontrole do familiar doente, que se torna mais agressivo e inquieto, causando um clima de intranqüilidade que foge aos padrões até então conhecidos pelos que com ele convivem e que afetam toda a estrutura familiar. Em face destes comportamentos, os familiares demonstram sentimentos de insegurança e medo, conforme os depoimentos a seguir:

[...] eu fico atento, nos casos de ele fechar o quarto, e a gente tem medo, está sempre de olho! (Diamante).

[...] antes nós dormíamos com a casa assim toda aberta, os quartos, e hoje a gente dorme com a casa toda fechada, o nosso quarto, o da minha menina fechada. Eu tenho medo, a gente nunca sabe o que vai passar na cabeça dele [...] (Rubi).

O familiar cuidador pode, também, apresentar ansiedade por não saber como lidar com alguns comportamentos apresentados como, por exemplo, o silêncio excessivo, fala contínua e desordenada ou com a imprevisibilidade em suas ações, e a percepção da vida cada vez mais "empobrecida" do paciente. Muitos não se conformam em ver um familiar, que até então era brilhante, cheio de projetos de vida e socialmente bem integrado, transformar-se numa pessoa comprometida, dependente, desprotegida e tomada por limitações de toda natureza. Os relatos abaixo expressam esta situação:

[...] assim, em ver a situação dela, a gente vendo a própria mãe na situação que ela está, uma pessoa que era, que fazia tudo e de repente está aí sem falar coisa sem é [...] então tu tem um sentimento assim de, de tristeza [...] (Esmeralda).

A doença mental não é apenas um rótulo, uma categoria, um diagnóstico, ela constitui-se numa experiência vivida pelo ser humano e por sua família. Alguns sintomas da doença trazem também, angústia e impaciência, decorrentes da necessidade de constante atenção e estímulo à ação. Um dos sintomas da doença mental é a diminuição da motivação, levando o doente a não conversar, ficar apático, isolado e retraído socialmente. ${ }^{12}$

A tarefa de cuidar e ao mesmo tempo ser um familiar exige também, muita disponibilidade e paciência, já que, muitas vezes, este é o único membro da família que acolhe o doente. Uma das participantes (filha) enfatizou a falta de interesse dos outros membros da família em se responsabilizar pelo cuidado da mãe, que vive com ela e fica somente sob os seus cuidados, como referido a seguir:
[...] eles acham que não tem compromisso e eles fazem só quando eles querem, entendeu [...] (Esmeralda).

O desejo dessa cuidadora era poder contar de maneira efetiva com o suporte emocional e a ajuda instrumental de outros familiares, isto é, poder compartilhar tanto as responsabilidades quanto o cuidar. As pessoas da família que não convivem diariamente com um portador de transtorno mental, mostram certo receio de se aproximar para ajudar nos cuidados, pois desconhecem e não compreendem a doença e suas manifestações ou, muitas vezes, nem se interessam em saber como podem ajudar, apenas se afastam desses membros da família.

O termo "sobrecarga familiar" fundamenta-se no impacto provocado pela presença do portador de sofrimento mental junto ao meio/ ambiente familiar e envolve aspectos econômicos, práticos e emocionais a que se encontram submetidos àqueles familiares que se encarregam do cuidado necessário e exigido pelo usuário. ${ }^{13}$ Os familiares com contato mais próximo a pessoa em situação de sofrimento mental usualmente não dispõem de tempo nem de espaço para manter outros relacionamentos. Envolvem-se apenas com o que diz respeito à doença mental, tornando o vínculo sobrecarregado de cobranças e exigências em relação a eles mesmos e à pessoa de quem cuidam. A distância entre a família e o corpo social pode ser exemplificada pela ausência a festas e eventos, diminuição do número de visitas a amigos e parentes.

A família do doente sempre procura uma causa para a doença e, ao longo de sua vida, tenta encontrar significados para compreender a origem do transtorno, pois, de certa forma, isto ocasiona certo alívio para os que estão envolvidos diretamente no processo. Neste estudo, constatamos que os familiares trouxeram concepções etiológicas de causas relacionadas a fatores hereditários e causas originadas de difíceis experiências em determinados percursos de suas vidas, ou de algum acontecimento marcante para os transtornos mentais de seus familiares. Para uma família, a doença foi percebida em um momento marcante da vida do familiar, como se segue:

[...] é, o "bipolar" mesmo apareceu depois! Na realidade [...] ele começou desde os 15 anos com depressão! Antes de casar! Com 15 anos ele teve uma depressão forte! É que, na realidade, deu o quadro mesmo com 23 anos (Diamante). 
A atenção e o cuidado dispensados ao paciente com transtorno mental são de fundamental importância, pois ele apresenta uma necessidade de atenção maior e contínua, parecendo ser essa uma das tarefas executadas pelo cuidador. Ao assumir tal função, o familiar cuidador passa a desempenhar diretamente o papel de observador, avaliador, determinando as ações e decisões a serem tomadas, surgindo assim o estresse e ansiedade pela transformação das situações vivenciadas. Este familiar passa a viver um cotidiano impregnado de preocupação. Nesse sentido, os transtornos mentais são vividos de maneira coletiva, pelo grupo familiar como um todo. Quando um membro familiar adoece, toda a sua rede de relações se altera, sendo a família, na maioria das vezes, o grupo primário de inserção de um indivíduo.

Para o autor referenciado, é necessário identificar possibilidades de intervenção e de ajuda junto à família, bem como efetivá-la como colaboradora e alvo do cuidado. Para tanto, esta precisa conhecer os vários aspectos relacionados ao transtorno e à terapêutica medicamentosa do familiar doente, como sinais e sintomas indicativos de recorrência e recaída, nome dos medicamentos prescritos, dose, efeitos terapêuticos e adversos dos mesmos, dentre outros. ${ }^{15}$

Esta situação é acentuada pela falta de informação, pois raramente a família busca ou recebe informações e, então, aparece insegurança quanto ao melhor modo possível de cuidar da pessoa doente. ${ }^{13}$ Os familiares que buscam suporte nos serviços de saúde mental apresentam demandas das mais variadas ordens, dentre elas, o desconhecimento da doença propriamente dita e do tratamento prescrito. ${ }^{15}$

A desinformação agrava a condição de fragilidade dos cuidadores, gerando impotência e podendo prejudicar sua saúde. Deste modo, faz-se necessário atingir o familiar cuidador com um suporte efetivo de auxílio, para que este possa atender seu ente querido de forma mais eficaz e com menos prejuízos na sua vida.

Nos encontros vivenciados entre o profissional que cuida e a família é que se dá o esclarecimento dos significados, que se encontra no processo de interpretação. ${ }^{11}$ Esclarecer significado é dar sentido, através da revelação daquilo que era e daquilo que será, tal como aparece agora. Interpretando ou esclarecendo aquilo que é neste momento, une-se ao que era e ao que será.

\section{O enfrentamento de dificuldades e limitações}

Uma das reações de uma pessoa que tem um membro da família acometido por algum transtorno mental é não aceitar, ou seja, negar ou esconder a doença perante os outros, como destaca o depoimento a seguir:

[...] ah, a maior dificuldade foi entender a doença, aceitar! [...] o bipolar tem cura, o bipolar tem tratamento, tem uma vida normal [...] (Diamante).

A partir do momento em que esta família ou esta pessoa busca informações a respeito e começa a entender a doença, o seu olhar muda e a sua concepção em relação à doença e possibilidades de enfrentamento estarão melhor estruturadas.

A experiência vivida e os significados que uma pessoa ou uma família dá aos seus problemas podem variar conforme o momento vivenciado no cotidiano. ${ }^{16}$

Ao envolver e dar suporte à família para enfrentar as dificuldades no relacionamento com o transtorno mental, podemos diminuir a carga emocional de todos os envolvidos na situação, aumentando o nível de interação e empatia da família com seu familiar doente. ${ }^{17} \mathrm{E}$ assim, também, diminuir a culpa, o isolamento social, a carência de informações, os problemas de vínculo com os profissionais de saúde, as situações de crise, as emergências e os conflitos familiares.

Já em relação ao aspecto de enfrentamentos das situações que a doença mental traz, o estigma e a discriminação tornam mais difícil, para as pessoas que sofrem de algum transtorno mental, reconhecer que tem algum problema, e procurar apoio e tratamento. ${ }^{18}$ A discriminação causa dano, destrói a autoestima, causa depressão e ansiedade, cria isolamento e também exclui socialmente.

Outro aspecto a ser considerado e que também está ligado à consciência e aceitação da doença é a aderência ao tratamento. Uma das maiores dificuldades é garantir o uso da medicação pelo paciente. Por diversos motivos, os pacientes não tomam a medicação corretamente, ou porque não se acham doentes, ou pelos efeitos colaterais que incomodam muito e, às vezes, por mero esquecimento, como refere o seguinte depoimento:

[...] ele que não aceita. Para ele, ele não tem nada! Para ele, ele é normal! [...] às vezes ele até entende que tem e outra hora não, mas ele não aceita que tem que tomar remédio, é bem complicado! (Rubi).

A aceitação da doença é parte fundamental para o sucesso do tratamento. ${ }^{12} \mathrm{O}$ portador 
de transtorno mental e sua família devem ser orientados sobre a doença e suas características, sobre o diagnóstico e prognóstico da mesma. Há necessidade de conhecimento, pois, em geral, o tratamento é por tempo indeterminado. As informações e orientações devem ser transmitidas pela equipe de saúde, de forma clara e objetiva, para que se estabeleça um vínculo de confiança e maior adesão ao tratamento.

O fato de a família conviver com o portador de transtorno psíquico, faz com que os seus membros fiquem sempre apreensivos quanto ao tratamento e surgimento de novas crises ou recaídas. Assim, o(a) enfermeiro(a) deve estar atento durante a assistência, observando como ocorre a dinâmica familiar, os significados que emergem em cada situação, dentro do ritmo próprio da família, procurando possibilidades com os cuidadores para transformar a interação familiar.

Outro tema de difícil enfrentamento, levantado pelos familiares, e também relacionado à suspensão do tratamento, é a questão do surgimento das crises, que acabam precipitando a necessidade de internação. Esta aparece como uma solução para a situação insuportável de ansiedade e temor que vivenciam as famílias quando percebem a emergência de uma descompensação e, em alguns casos, pode representar uma tentativa de manutenção da estrutura familiar. Como podemos observar a seguir:

[...] ele ameaçou botar fogo na casa, estava totalmente fora, não estava violento assim [...] e a gente entrou em conversa com ele e conseguimos levar ele sozinho, eu e a Rubi, internamos e ele aceitou até a internação lá [...] (Diamante).

Ao falar da complexidade do cuidado ao portador de transtorno mental, é possível compreender a ambigüidade vivenciada pelo familiar quanto ao parente permanecer em casa ou no hospital. Ao mesmo tempo em que gostaria que ele permanecesse em casa, para receber cuidados e afeto, considera o hospital uma alternativa para garantir o controle do quadro de crise e a administração de medicamentos, para poder dar continuidade ao tratamento.

Deste modo, cada ser humano transcende com as possibilidades de que dispõe em diferentes momentos de sua existência. ${ }^{11}$ Em sua singularidade, ele se depara com limites, os quais são transcendidos de acordo com o padrão de relações que estabelece consigo e com os outros. Com isso, cada ser humano é indissociável de seu meio, influencia e é influenciado em suas decisões, o que lhe confere uma liberdade situada. Daí a necessidade de uma assistência profissional às famílias que convivem com um portador de transtorno psíquico com um olhar mais voltado à qualidade de vida da família e dos que praticam este cuidado.

\section{A interrelação em família e com "outros"}

Durante toda a trajetória de vida destas famílias, elas se deparam com inúmeras vivências que representam algum significado em cada fase da vida, especialmente quando estão ligadas ao familiar que adoeceu. Nos relatos de uma família destacam-se alguns pontos importantes que fizeram parte das relações interpessoais que ocorreram com o familiar doente, bem como os significados atribuídos a estas passagens.

Em relação à moradia, ao estudo e ao trabalho, os familiares cuidadores, Rubi e Diamante falaram desta relação com o familiar da seguinte forma:

[...] sempre morou conosco! Sempre morou, sempre trabalhou! Com 13, 14, 15 anos ele começou a ajudar na padaria! Fez primeira comunhão, fez tudo direitinho, na Igreja! Se formou na oitava [série do ensino fundamental], depois no terceiro [ano do ensino médio]! Começou a namorar, parou de trabalhar. Ele já fez administração, já passou para direito, mas depois pode querer ir, pode não querer ir e lá vai, entendeu, uma confusão (Diamante).

Quanto ao convívio familiar e aos relacionamentos afetivos e de amizade, ressaltam os seguintes depoimentos:

[...] é, ele tem um convívio, ele tem e a gente também tem muita amizade. A gente é bem querido lá e todo mundo adora ele e aquelas igrejas, o pessoal vai lá em casa e qualquer religião, qualquer crença, fazendo corrente pro meu filho (Diamante).

A Teoria do "Tornar-se Humano" ${ }^{\text {, }}$, em seus princípios, afirma que o humano co-existe enquanto co-constitui padrões rítmicos com o ambiente que o cerca. A vida é uma manifestação de vibrações rítmicas. Criamos padrões rítmicos com o universo. Esses padrões são os paradoxos que vivemos ao longo da vida. Paradoxos são ritmos vividos de forma multidimensional e simultânea. Cada pessoa tem seu ritmo que se move junto com o das outras pessoas. Neste estudo, o convívio com a família e com o meio está diretamente relacionado às implicações na vida do ser humano e nos padrões de inter-relacionamento que vão se constituindo. Assim, os processos de relações paternais, fraternais, conjugais e outros, vão formando uma rede de experiências vividas. 
No entanto, nem todos os familiares possuem condições estruturais, econômicas e emocionais para lidar com o comportamento próprio do membro da família acometido de um transtorno mental. Daí a complexidade na qual se insere o cuidador, que passa a vivenciar situações que, muitas vezes, se refletem direta e indiretamente em sua subjetividade, exposta não só nas situações determinadas pelo membro da família com transtorno mental, mas também nas situações conflituosas geradas no próprio contexto familiar.

É muito complicado, porque a pessoa que não tem uma estrutura, conhecimento [...] (Diamante).

Ah, é muita responsabilidade! Eu comecei a me envolver, fui ficando, é como ter um filho e agora tem que cuidar, entendeu! (Esmeralda).

A complexidade das interações em família e com os outros reflete a unidade família-meio ambiente e, consequentemente, a dinâmica e criativa interação do todo que compõe esta unidade, que é mais do que a soma dos aspectos físicos, mentais, emocionais, sociais, espirituais e materiais de nossa vida. Entendemos este conjunto como um "sistema de saúde" que, dependendo da harmonia de seu ritmo, responde pelo bem-estar do ser humano. Deste modo, as experiências de vida refletem a natureza paradoxal das relações da pessoa no mundo em um processo rítmico. A Teoria do "Tornar-se Humano" ${ }^{\prime \prime}$ afirma que a essência da enfermagem é o relacionamento enfermeiro-pessoa e a sua meta principal é a qualidade de vida sob a perspectiva da própria pessoa. ${ }^{9}$

\section{A co-criação das possibilidades de transcen- dência}

Para compreender o que é ser um cuidador de um portador de transtorno mental, é preciso transportar-se para o seu mundo, imaginar-se no lugar dele ${ }^{20}$ não é suficiente para isso o embasamento teórico. É preciso atentar-se para o caminho da solicitude, num esforço de ser-com-o-outro, com disponibilidade para compreendê-lo em tal momento de sua existência. Para o familiar cuidador, a doença é um obstáculo a ser superado e a esperança de uma melhora está sempre presente, principalmente quando o seu entendimento da doença está firmado. Há que ser lembrado que estas famílias estão passando por situações não escolhidas e para as quais não foram preparadas. Portanto, o estar nesse papel é difícil e sempre acarreta algum prejuízo para a família. Porém, muitas dessas famílias conseguem se restabelecer e manter uma estrutura adequada para o cuidado ao doente. Com um acompanhamento profissional e tratamento apropriados, a família tem o apoio necessário para poder transformar sua prática na busca da qualidade de vida.

Para Diamante e Rubi, suas atitudes no diaa-dia estão constantemente sendo mudadas, pois eles passaram para a uma fase em que a doença já foi compreendida e as informações a respeito estão sendo aperfeiçoadas.

[...] eu acho que cada dia a gente vai aprendendo mais, vai aceitando, vai caindo na realidade! [...] nós já aceitamos que ele é doente e que tem que tratar e nós é que temos que cuidar dele! (Diamante).

Para esses familiares, a esperança de uma melhora é o que os sustenta para continuarem o tratamento de seu familiar, já que não existe cura para a doença. A adesão ao tratamento constituise no co-transcender as possibilidades a fim de procurar maneiras únicas de iniciar o processo de transformação na busca pela qualidade de vida, exemplificado nas falas: [...] (Rubi).

[...] a gente tem esperança que ele vai melhorar

[...] é a esperança a gente tem! Que eu espero um dia de ele aceitar o tratamento, que o tratamento já é bem dizer, uma cura! (Diamante).

Co-transcender significa mover-se para outras dimensões com sonhos e esperanças cultivados, criando novas formas de perceber o que já é conhecido. ${ }^{9}$ Quando a pessoa co-transcende, cria forças para originar novas formas de viver, transformando assim, seus padrões de vida. Transformar é viver novas possibilidades imaginadas. A mudança é um processo contínuo do ser humano em interação com o meio ambiente, movendo-se do que é para o que ainda não se é. As novas maneiras de ver a vida são incorporadas às anteriores.

Para Esmeralda, a esperança de que sua mãe melhore se apóia na idéia de que ela possa vir a se tornar mais independente, voltar as suas atividades diárias e também, retornar ao trabalho, o que foi relatado da seguinte forma:

[...] ela já esteve pior, hoje ela está melhor do que antes, mas, eu claro que a minha esperança é que ela fique cada vez melhor, [...] que ela pudesse ficar sozinha, entendesse, é que no caso se eu trabalhar, que ela pudesse ficar sozinha em casa [...] (Esmeralda).

As transformações buscadas pelo ser humano são reforçadas nos conceitos de enfermagem, entendidos como ciência e arte, fundamentadas nas ciências humanas. ${ }^{11} \mathrm{O}$ foco da enfermagem é 
o ser humano como unidade de vida, como um elemento de participação qualitativa em seu modo de experenciar a saúde.

\section{CONSIDERAÇÕES FINAIS}

O presente estudo teve por objetivo compreender os significados de ser familiar cuidador do paciente portador de transtorno mental. O referencial teórico utilizado fundamentou esta pesquisa voltada ao familiar cuidador do portador de transtorno mental, o qual nos possibilitou uma melhor compreensão do mundo em nossa volta, contribuindo para a descoberta de novos significados e reflexões. Com a teoria do "Tornar-se-Humano", pudemos co-existir e co-constituir padrões de interrelação com os familiares cuidadores na busca pela co-transcendência. $O$ foco principal da teoria diz que a busca de possibilidades para SER MAIS com qualidade de vida confere ao ser humano uma maior autonomia, no que diz respeito às decisões e ações de saúde, com base no processo reflexivo.

A compreensão da doença pela família e a busca pela assistência mais adequada ao seu familiar doente acontecem de forma lenta e progressiva, à medida que eles se dão conta do processo pelo qual estão passando. Na interrelação em família e com outros, a família revela e oculta ao mesmo tempo que estão se tornando o que encarnam, o que foram e o que são. A família é capacitada e limitada simultaneamente por suas escolhas. Ao moverem juntos ou separados, ao mesmo tempo, a família ora se conecta, ora se separa do ambiente, em busca de uma melhor qualidade de vida. $\mathrm{O}$ movimento de revelar-ocultar está presente, por exemplo, quando a família, inicialmente, não aceita o diagnóstico da doença mental, quando nega ou esconde a doença perante os outros. No entanto, à medida que a família sente-se esclarecida, começa a entender a doença e a desenvolver estratégias de enfrentamento. Este movimento nem sempre é unidirecional, mas multidirecional, tendo em vista que comporta avanços e recuos, com padrões ritmicos específicos de cada família.

Percebemos neste estudo que, na assistência psiquiátrica, o enfermeiro atua além de suas funções técnicas, como interceptor para criar e manter um ambiente terapêutico e estabelecer relações interpessoais terapêuticas não só com os pacientes, mas também com seus familiares.

Deste modo, viver a teoria do "Tornar-se Humano" com o familiar cuidador e o portador de transtorno mental, implica na co-participação do (a) enfermeiro (a) na iluminação de significados das situações vivenciadas e mover-se com eles na escolha de possibilidade de melhor qualidade de vida, através de uma participação inter-subjetiva. Neste processo, o familiar cuidador, o portador de transtorno mental e $o(a)$ enfermeiro(a), enquanto unidade de vida, transcendem seu tempo-espaço, bem como suas próprias condições de ser e agir no mundo.

Desta forma, a teoria do "Tornar-se Humano" constitui-se em novo paradigma para o "ser" e "fazer" enfermagem, dentro de uma abordagem mais humanizada, moderna, inovadora e desafiadora, centrada na pessoa com doença mental e sua família, focando os valores e experiências vividas por estas pessoas, respeitando seus ritmos e acreditando em suas potencialidades de co-transcender para ser mais.

\section{REFERÊNCIAS}

1. Ministério da Saúde (BR), Departamento de ações programáticas estratégicas. Departamento de atenção básica, Coordenação geral de saúde mental, Coordenação de gestão da atenção básica. Saúde mental e atenção básica: o vínculo e o diálogo necessários. Brasília (DF): MS; 2003 [acesso 2007 Out 15]. Disponível em: www.saude.gov.br

2. Bandeira M, Barroso SM. Sobrecarga das famílias de pacientes psiquiátricos. J Bras Psiquiatria. 2005 Jan-Mar; 54(1):34-46.

3. Barroso SM, Bandeira MN. Fatores preditores da sobrecarga subjetiva de familiares de pacientes psiquiátricos atendidos na rede pública de Belo Horizonte, Minas Gerais, Brasil. Cad Saúde Pública [periódico na Internet]. 2009 Set [acesso 2011 Jan 17]; 25(9):1957-68. Disponível em: http:/ / www. scielo.br/scielo.php?script=sci_arttext\&pid=S0102311X2009000900010\&lng=pt

4. Moreno V. Familiares de portadores de transtorno mental: vivenciando o cuidado em um centro de atenção psicossocial. Rev Esc Enferm USP [periódico na Internet]. 2009 Set [acesso 2011 Jan 17]; 43(3):566-72. Disponível em: http://www. scielo.br/scielo.php?script=sci_arttext\&pid=S008062342009000300010\&lng=pt

5. Moreno V, Alencastre MB. A trajetória da família do portador de sofrimento psíquico. Rev Esc Enferm USP [periódico na Internet]. 2003 Jun [acesso 2011 Fev 07]; 37(2):43-50. Disponível em: http://www. scielo.br/scielo.php?script=sci_arttext\&pid=S008062342003000200006\&lng=pt

6. Moreno V. A família do portador de sofrimento psíquico: olhares, trajetórias percorridas e possibilidades. Ribeirão Preto (SP): Legis Summa/ FIERP, 2005. 
7. Stuart GW. Papéis e funções dos enfermeiros psiquiátricos: cuidado competente. In: Stuart GW. Laraia MT. Enfermagem psiquiátrica: princípios e prática. $6^{\mathrm{a}}$ ed. Porto Alegre (RS): Artmed; 2001. p. 36

8. Stefanelli MC, Fukuda IMK, Arantes EC, organizadores. Enfermagem psiquiátrica em suas dimensões assistenciais. São Paulo (SP): Manole, 2008.

9. Parse RR. Illuminations: the human becoming theory in practice and research. New York (US): National League for Nursing; 1995.

10. Ministério da Saúde (BR), Conselho Nacional de Saúde, Comissão Nacional de ética em Pesquisa. Resolução no 196, de 10 de outubro de 1996: diretrizes e normas regulamentadoras de pesquisas envolvendo seres humanos [online]. Brasília (DF): MS; 1996 [acesso 2010 Abr 08]. Disponível em: http://conselho.saude.gov.br/resolucoes/1996/ Reso196.doc.

11. Hickman JS. Rosemarie Rizzo Parse. In: George JB. Teorias de enfermagem: os fundamentos para a prática profissional. Porto Alegre (RS): Artes Médicas; 2000. p. 268-85

12. Louzã MR, Elkis H. Esquizofrenia. In: Louzã Neto MR, Elkis H. Psiquiatria básica. $2^{\mathrm{a}}$ ed. Porto Alegre (RS): Artmed; 2007. p.18.

13. Pegoraro RF, Caldana RHL. Sobrecarga de familiares de usuários de um centro de atenção psicossocial. Rev Psicologia em Estudo. 2006 Set-Dez; 11(3):569-77.

14. Navarini V, Hirdes A. A família do portador de doença mental: identificando recursos adaptativos. Texto Contexto Enferm. 2008 Out-Dez; 17(4):680-8.

15. Monteschi MV, Kelly GG, Miasso AI. Terapêutica medicamentosa: conhecimento e dificuldades de familiares de pessoas idosas com transtorno afetivo bipolar. Texto Contexto Enferm [periódico na Internet]. 2010 Out-Dez [acesso 2011 Jan 17]; 19(4): 709-18. Disponível em: http://www.scielo. br/scielo.php?script=sci_arttext\&pid=S010407072010000400014\&lng=pt

16. Ribas DL, Borenstein MS, Padilha MI. Iluminando as vivências de indivíduos em sofrimento psíquico de um CAPS em Florianópolis. Texto Contexto Enferm. 2007 Jan-Mar; 16(1):40-6.

17. Coimbra VCC, Guimarães J, Silva MCF, Kantorski L, Scatena MCM. Reabilitação psicossocial e família: considerações sobre a reestruturação da assistência psiquiátrica no Brasil. Rev Eletr Enfermagem [periódico na Internet]. 2005 [acesso 2007 Out 10]; 7(1). Disponível em: http://www.fen.ufg.br/ revista/revista7_1/pdf/REVISAO_01.pdf

18. Associação Brasileira de Familiares, Amigos e Portadores de Esquizofrenia (BR). Transtorno mental [online] [acesso 2007 Out 15]. Disponível em: http:/ / www.soesq.org.br

19. Portela CM. O cuidado ao familiar cuidador de portadores de transtornos de humor na rede básica de atenção à saúde [dissertação]. Florianópolis (SC): Universidade Federal de Santa Catarina, Programa de Pós-Graduação em Enfermagem; 2006. 